\title{
A Discourse Analysis Study of Comic Words in the American and British Sitcoms
}

\author{
Bushra Ni’ma Rashid ${ }^{1}$ \\ ${ }^{1}$ the University of Baghdad, College of Education, Ibn Rushd for Human Sciences, the Department of English, \\ Iraq
}

Correspondence: Bushra Ni'ma Rashid, Assistant Professor, the University of Baghdad, College of Education, Ibn Rushd for Human Sciences, the Department of English, Iraq. E-mail bushra.nima@ircoedu.uobaghdad.edu.iq

Received: March 11, 2019 Accepted: April 17, 2019 Online Published: June 27, 2019

doi:10.5539/ijel.v9n4p70 URL: https://doi.org/10.5539/ijel.v9n4p70

\begin{abstract}
This paper investigates discourse analysis and its role in studying comic words and their meaning in different contexts. This study aims at showing the relation between discourse analysis and comedy or comic words, presenting the types of comedy and comic words and how they give meaning of mocking, teasing and sarcasm, presenting the difference between mocking, teasing and sarcasm, displaying interjections and their relation with comic words, in addition to analyzing the data in terms of tables. It is hypothesized that many people do not know the meaning of discourse analysis and comedy. Second, they do not have the capacity to differentiate between comedy, mocking, sarcasm and teasing. They also do not know how to use comic words in expressions. Above all, many of them cannot analyze a particular episode properly and people cannot know the intentions of the speaker concerning comic words. The value of this study is for people who are interested in linguistics. The data used in this study are the American sitcom 'Friends' and the British one titled 'Bottom'. The data is analyzed on the basis of the theories of the Cooperative Principle and Taflinger model. The results of "Friends", the American sitcom and "Bottom", the British one, show that there are many comic words. The characters use interjections or onomatopoeia to communicate laughter and excitement. The use of teasing is also emphasized by the use of other comic words like: a*s, breasts, and idiot for presenting jokes and laughter sense.
\end{abstract}

Keywords: discourse analysis, comic words, mocking, teasing and sarcasm

\section{Introduction}

\subsection{Preliminary Remarks}

This paper highlights the correlation between comedy and discourse analysis, or the analysis of comic words in American and British sitcoms. Comedy is considered as a type of discourse that is used for the sake of humor in order to amuse the hearers or the participants in the discourse. It introduces laughter that is characterized as a human behavior which makes humans elucidate their purposes, intentions and opinions in social interaction. Comedy is presented in any medium of entertainment. For instance, theatre, television, film, stand-up comedy, sitcoms etc.

Many issues are tackled in this study. First, people misunderstand what is meant by discourse analysis, comedy, comic words in specific and the use of comic words in American and British sitcoms. Second, many people do not know how to analyze a piece of discourse and show how the comic words are used. Third, presenting and recognizing comic words are somehow a problematic matter for people, because they sometimes cannot decide the exact use of words or to which type, they belong. Moreover, a great number of people may misunderstand the communicative intentions behind saying a specific comic word and they might use such words with the wrong people and in wrong situations.

This study is established on many steps. The first step is defining discourse analysis as a pathway to other terms. The second step is presenting the meaning of discourse analysis, comedy, types of comedy, comic words, comics. The third one is explaining the connection between comedy and mocking, teasing and sarcasm. The fourth step is presenting the difference between mocking, teasing and sarcasm. The fifth step is displaying interjections and their relation with comic words. The sixth step is showing a number of episodes from both American and British sitcoms. The last step is analyzing the data by putting them in tables. 


\subsection{Significance of the Problem}

Common discourse is often filled with all kinds of comic elements. In fact, some spice is added to speech and interaction through comic words, teasing, mocking, sarcasm, interjections and so on. Very often, people fail to understand the purport of the words and expressions they use. Linguists however, are highly interested in analyzing conversations and understanding the overt and covert implications of utterances. Sitcoms are very popular and have a large audience the world over. Sitcoms represent real life situations, informal talk and natural interactions among all kinds of characters. Like all other elements of speech, sitcoms contain comedy, comic words, interjections, speech acts, mockery, sarcasm and teasing. These are natural to human beings. The best place where they can be found for study are sitcoms.

The researcher has selected a few sitcoms that serve as examples of comedy and humor. On the basis of the analysis of these examples, the researcher has tried to point out the humor creating strategies, their implications, types and usage. For linguists and scholars, the study offers a detailed analysis and deep understanding of comic and humorous features in natural speech. For the laymen, it creates an awareness about the desirable and undesirable impact of mockery, teasing etc. so that people will be careful while using them. The intention is to make participants wary while using words and understand that speech can make and break relationships. There are thin lines that divide light-hearted teasing and sarcastic comments. Mockery may be humorous for others but hurting for the person being mocked at. An awareness and understanding of these terms and the speech in which they are reflected will certainly enable people to use words carefully.

Comic words mocking terms and sarcastic comments are governed by culture. Hence, the researcher has selected British and American sitcoms. The two separate selections give an opportunity to compare humor in the two different countries although the language is common to both.

\subsection{Relevant Scholarship}

A new study should start logically with research conducted previously in the same field. The researcher has given few but significant references of similar studies conducted in the past. They not only give a preview of related literature but serve as a foundation for the current study. They allow the researcher to decide the methodology to be used for discourse analysis to make it effective and fruitful.

1) Eduardo (1998) conducted a study which is entitled Situating Laughter: Amusement, Laughter, and Humor in Everyday Life.

According to the researcher certain phenomena seem obstinately hidden from the lenses of scientific tools and microscopes. Least visible of all, perhaps, lurks the man behind the lens; and within him, behind his eye, his seeing, thinking, and feeling 'I'. In recent times, the scientific (and social scientific) endeavor has been shaken by glimpses of self-awareness. The researcher focuses on the characteristic features that human beings share with each other. It borders on the chit-chat between men and women in the lab coats (or in the pin-striped suits, uniforms, aprons, and overalls); in the bars, cars, and homes to which they retire after work; among the gossip, temper tantrums, joking, and lust which color their daily experience. Laughter is something the reader will need little introduction to, as a human being. Nevertheless, to the scientist it represents a baffling and objectionable intruder; an embarrassing glimpse of himself. Unlike anger, happiness, or fear, humor appears to lack a simple, commonsense cause or purpose. The phenomenon has remained largely unstudied throughout the development of the human and social sciences.

2) Li (2016) conducted a study entitled "A Pragmatic Analysis of Humor Words in English Advertisements."

Pragmatics has been an independent discipline for the last thirty years and is thus a young discipline comparatively. As a medium emerging commonly in advertising language art, humor has attracted wide attention of many producers. Previous scholars analyzed more from the perspective of grammar, vocabulary, rhetoric, etc. But the research of advertising language humor is lacking from the aspects of pragmatic rules. The collection of data is quite open in this study. Any advertisement that can be transcribed into written form is part of interest. They are excerpted from magazines, advertisement, collecting books, newspapers, TV and radio commercials. As the focus is only on language humor, situational humor produced by visual performance is not involved in this thesis. The advertising language art of humor has been widely paid attention. Based on the existing theories of humor research, author of this paper used many kinds of pragmatic theories to analyze English advertising humor language, including reference, deixis, anaphora, presupposition, speech act theory, the cooperative principle, conversational implicatures, and the politeness principle. It can not only provide reference for the research of this field for later scholars, but also provide theoretical guidance for the AD makers of using humor language to produce a good advertising effect. 
3) The third study is conducted by Green (2016) which is entitled Impact of Comedy on Racial and Ethnic Discourse.

An overwhelming facet of race literature suggests that American society has entered an era of colorblindness; where instead of perpetuating racist ideology through blatant discriminatory legislation, racial differences are either understated or ignored entirely. These new racial processes are reflected in the policies of major social institutions, but also within popular culture. Yet, as made evident by the success of comedians such as Chris Rock and Dave Chappelle, stand-up comedy challenges acceptable racial discourse placing race in the forefront. Comedy persists as a facet of popular culture where racial difference is made apparent, yet ironically the art of comedy is usually overlooked by sociologists. What is lacking in the humor research is an understanding of how comedy creates an environment where race can be spoken about directly, and often times harshly. Through the analysis of focus groups, the present study finds evidence to suggest that racial and ethnic comedy serves to both reinforce and wane racial and ethnic stereotypes, similarities, and differences. After watching stand-up comedy clips of popular comedians, black and white respondents show both agreement and disagreement on: (1) the offensiveness of ethnic comedy (2) stereotypes and perceived truths and (3) the utility of ethnic comedy in everyday interactions. These findings are helpful in understanding how comedy serves as one of the few openly racialized facets of popular culture as well as uncovering some of the ways in which race works within the culture of a self-proclaimed colorblind society.

In addition to this is the study Paper Comics, Linguistics, and Visual Language: The Past and Future of a Field which is submitted by Cohn (2012).

The current study is entitled: A Discourse Analysis Study of Comic Words in the American and British Sitcoms.

The current study is different from the previous studies in that it deals with studying comic words specifically and relate them with discourse analysis. It takes into consideration the two different cultures which are American and British. This study deals with sitcoms, not with action, racism, or tragedy movies. This paper investigates discourse analysis and its role in studying comic words and their meaning in different contexts. The importance of this study is denoted by the connection between discourse and comedy or humor, the difference between comedy, mocking, teasing, and sarcasm. The significance of this study is also emphasized by the two kinds of interjections, onomatopoetic words, mocking, teasing, and sarcasm serve as kinds or types of comic words in American and British sitcoms.

The current study differs from the previous studies in many issues. Concerning the first previous study, which is Situating Laughter: Amusement, Laughter, and Humor in Everyday Life, the current study differs in that it studies comic words specifically. The study is discourse analysis, it does not concern with studying comic words from a sociolinguistic point of view. In differs also in using different data which are the American and British sitcoms. The current study is similar to the first previous study in that it deals with humor, laughter or comedy as a general concept.

Regarding the second previous study, which is entitled "A Pragmatic Analysis of Humor Words in English Advertisements," the current study studies comic words from a discourse analysis point of view. It also deals with comic words which are different from humor words in that they are usually onomatopoeic words. The similarity between the two studies is that both use the Cooperative Principle as a model for analysis.

In addition, the differences and similarities between the third study which is entitled: Impact of Comedy on Racial and Ethnic Discourse and the current study are also important to be mentioned. The current study differs from the third previous study in that the type of discourse is not specified from the title and it uses discourse analysis in general. Above that, the current study deals with sitcoms. Meanwhile, the third previous study deals with stand-up comedy and racial and ethnic discourse. The current study is similar to the third previous study in that they both deal with comedy in everyday interaction.

\subsection{Method}

This study is descriptive and analytical in nature. The assumption is that although discourse is common and natural to human beings who are social, few have complete understanding of various elements of discourse, especially humor, which elucidates discourse. Even fewer people know how to analyze discourse and understand it in depth.

Humor in discourse is reflected in common situations. Sitcoms represent such situations and the characters in sitcoms resemble ordinary human beings. Hence, the method used for understanding humor creating devices like speech acts, interjections, mockery, sarcasm etc., the relationship between them and their impact, the researcher decided to select extracts from two sitcoms, one British and one American. 
The findings are based on a detailed analysis of the selected extracts, presented in a tabular form.

\section{Operational Terms}

\subsection{Discourse}

To begin with, the term discourse is defined by Matthews (2005) as any combination of sentences in written form or any series of speech events in which sequential sentences or utterances come together. This term is used for both spoken and written language, or for any model of language used for any study. Discourse is not restricted to sentence boundaries. It is something that passes the limits of sentences. In other words, discourse is any coherent sequence of sentences, spoken or written. According to Johnstone (2008) discourse, denotes actual patterns of communicative action that occur in the medium of language, or it is the "meaningful symbolic behaviour".

Discourse analysis is presented as how language-users understand and judge what they read in texts, comprehend what speakers mean by their utterance regardless of what they say, recognize the relationship between language and the social and cultural contexts, and take part in the activity of conversation. It also examines how relationships between participants can influence the use of language. Jaworski and Coupland (2014) state that discourse analysis falls into three classes: (1) what is beyond the sentence pattern, (2) the use of language, and (3) the variety of social practice and behaviour which consists of instances of language that are non-linguistic and nonspecific.

According to Johnstone (2008), discourse analysis is defined as the study of language in everyday sense. It is demonstrated by the meaning of people when saying that language is talk, communication, and discourse. Some discourse analysts define 'discourse' as actual instances of communicative action in a particular situation. Meanwhile, others define it as 'meaningful symbolic behaviour'. Beside discourse is the word 'analysis' which means breaking down text into its smallest constituents according to different principles; or it is the process of taking thing apart just like chemical analysis.

Van Dijk (1997) says that discourse is not only concentrating on the order and form of words and sentences. It focuses also on analyzing sound, sight and body; more accurately, auditory sounds, visual marks (letters, figures, colors, etc.), computer screens, emphasis, volume, gestures, face-work, bodily position, laughs, behavior, face-to-face interaction, the speaker and the hearer, talk and text, meaning, styles, rhetorical structures and schemata.

\subsection{Comedy}

A comedy can be defined as a work in which the materials are chosen and ordered so as to amuse and interest people: the characters attract the persons' delighted attention because the latter feels that no disaster will happen and the action is happily done. The term 'comedy' is usually applied to plays and the comic form also occurs in narrative poetry and prose fiction (Abrams, 1981).

The essential function of comedy is amusement. This amusement could be ranged from a calm smile to a loud laugh (guffaw).

Laughter creates laughter; this means that a little thoughtless laughter creates thoughtful laughter. Almost always comedy presents different situations that are more potential, serious, and believable than farce. The laughter of comedy can be "warm laughter" in which people pass through problems with one another. It can also be "corrective laughter" of satire which is directed from a gentle to a savage one. The comedy of ideas uses situations and employs characters to create "thoughtful laughter". All comedy, as the branches of a tree that are related to the trunk, is related with the sense of humor or comic vision (Attenbernand \& Lewis, 1989).

Aristophanes as mentioned in Silk (2002), presents comedy as it is filled with jokes and comic configurations. One of his comments regarding comedy is that it is difficult for people to deal with, because it presupposes a culture whose people's literary perspective are almost narrow. It is remarkable to consider the specifics of Aristotelian which are based on one general principle: tragedy is high, but comedy is low. Comedy makes people laugh and the more modern principle is that it is intellectual, because it provokes thinking, thus, thoughtful laughter. So, comedy works on judgments and fancy. Comedy is associated with excitements very often (comedy thrillers) or with fear (horror comedy). Consequently, comedy is painless and tragedy is painful, Silk (2002), Obviously, it is not sufficient to say that comedy just evokes laughter and has a joyful ending. Sometimes, there can be laughter in tragedy; and tragedy may end with a happy event (Brooks \& Heilman, 1999).

\subsection{Types of Comedy}

There are different main types of comedy that are listed under the comedy type: 


\subsubsection{Comedy of Errors}

It is a type of comedy in which there are a number or series of mistakes of fact or identity in a particular text. These are called misinterpretations of actions or characters. It is one of the most familiar conventions of a written text in which such mistakes might occur in texts than in real life.

\subsubsection{Comedy of Manners}

It is a type of comedy which laughs and satirizes the manners and affections of the characters or the society. So, it is a film, play or novel that satirizes the behaviour within a particular-community (Stone \& Nettleton, 1914).

\subsubsection{Sentimental Comedy}

A type of comedy which combines and mixes two elements like seeking to play upon people's feelings, sympathies and nostalgia with making them laugh; there might be simple tears because of putting together these two nice combinations. The piece of a discourse is called weepy and sentimental since its focus is on sentiment, tenderness, sensitivity, and the use of emotional expressions, (Lynne \& Kosove, 1977).

\subsubsection{Comedy of Humors}

The Elizabethan playwright Ben Jonson establishes a physiological theory of four humors. Four primary fluids of the body (blood, phlegm, choler (yellow bile), and melancholy (black bile) which determine the person's physical and mental qualities. According to the humoral theory, these four conditions cause abnormalities, (Abrams, 1981).

\subsubsection{Farce}

Farce is a component in the comic episodes. It is designed to provoke the audience to simple, hearty laughter, or belly laughs in the language of films, drama, and certain funny episodes. It aims at producing or employing exaggerated types of characters and put them in unsuitable situations in order to make use of verbal humor.

\subsection{Comic Words}

Comic as an adjective which means "funny", or as concerning with comedians in which a confusion is caused and avoided in most cases. Comic words show like a complete nonsense if they occur out of the overall context, because they lose their meaning in isolation. But sometimes they appear to be funny alone depending on the paralinguistic features; like body language, gestures, facial expressions, tone, etc. Another characteristic of comic word is that they are often onomatopoeic words and interjections, in addition, they are written sometimes with boldface.

List of certain comic words:

1) Zap! (it expresses a sudden change and a hit with a lot of force).

2) Kapow! (a cry within a battle and a noise made after success).

3) Wow! (a word that is used for a thing or a person that is pleasant, attractive and successful).

4) Pow! (a word which shows the noise of an explosion or a gun being shot).

5) Doozy (something really great).

6) Whee (an exclamation of excitement or delight)

7) Troglodyte (someone or something which lives in a cave).

8) Bloviate (speaking pompously) (Taylor, 2006).

9) Bwah-hah-hah (indicates triumphant laugh)

10) Ew (denotes disgust)

11) Ha (expresses joy or surprise)

12) Ha-ha (communicates laughter)

13) Har-har (communicates mock amusements)

14) Hee-hee (shows a mischievous laugh)

15) Oh (expresses emotions to a pleasure or pain)

16) Ooh (conveys interest or admiration)

17) Whoop-de-doo (expresses mocking reaction) 
18) Woo (excitement)

19) Yuk (a laugh)

20) Zing (expresses laughing ironically) (Aragones \& Dunn, 2013).

21) Damn or hell.

22) Hey (Ameka, 1992).

The variation of cultures, social structure, values, ideology, semiotics and other factors form a difficulty in recognizing comic elements or making the listeners laugh at things which are not intended to be funny in a particular text. Moreover, the comic language is considered to be highly idiomatic or it contains idioms; thus, it is difficult to be interpreted. Comic words or elements are highlighted by expressions and tone of voice in addition to non-verbal ways of indicating speech acts. Forms of the comic-humor, joking, punning, irony, word play, satire, and parody are speech acts. Hence, they are basically ambiguous.

\subsection{Mocking}

Comedy is defined as a game played to throw its reflections upon social life. It is an instrument that is considered as a type of discourse that is used for the sake of humor in order to amuse the hearers or the participants in the discourse. On the contrary, according to the lexicographers, to mock means to deride, to laugh, to ridicule, to deal with people with scorn and contempt. When someone talks to or about someone else in a mocking sound, he or she is making fun of them in a mean and an unpleasant way (Evaldsson, 2005).

\subsection{Teasing}

Teasing is considered as important and central to human social life. The purpose behind teasing is to socialize, flirt, resolve conflicts, and pass the time in imaginative and playful ways. Teasing can lead to more disturbing ends if it humiliates or harasses. Teasing is often included and at times mixed with, humour, play, irony, sarcasm, and bullying. Furthermore, teasing is a process of relations that requires the interaction between individuals, (Kruger et al., 2006).

\subsection{Sarcasm}

Defining sarcasm is the same as defining irony. It is an elusive thing; words do not convey the main essence of sarcasm, by contrast, it is like a person knows sarcasm when he sees it. Sarcasm is the capacity for insulting idiots without their realizing. According to Oscar Wilde, as mentioned in Naccarato and Dorfman (2017), "The lowest form of wit but the highest form of intelligence". It is considered to be the body of natural defense against stupidity (Naccarato \& Dorfman, 2017). Meanwhile, comedy is considered as a type of discourse that is used for the sake of humor in order to amuse the hearers or the participants in the discourse.

\subsection{The Difference Between Mocking, Teasing, and Sarcasm}

Mocking means laughing at someone in an unkind way. So, it is as making fun of someone scornfully. It does not necessarily be used in humorous environment (intentionally meant). (McDowell et al., 2011). For instance:

a. Sir, could you repeat the answer please?

b. Yes, of course.

c. He could not understand the explanation (laughing).

a. You are always making fun of me.

Teasing signifies also laughing at someone or saying bad things, either for the purpose of joking in a playful way or when someone wants to upset someone else. It depends on the intention of the speaker. (unintentionally said and sometimes intentionally meant) (Reddy, 1991). For example:

a. Stop teasing him about his weight

b. I am just making him hate food.

a. No, you are making him upset

So, the difference between mocking and teasing is that mocking causes pain and it is mean-spirited. On the contrary, teasing always means to be used in humorous environment so as to point out to something wrong. Thus, mocking is stronger than teasing. While sarcasm is something different from mocking and teasing.

Sarcasm is differentiated as the use of wit and remarks to imply the opposite of what the speaker says. It is done for two intentions: either to hurt someone's feelings or to criticize him or his actions, but in a funny or humorous way (Boxer, 2002). For instance: 
a. You have been doing well in the exam (the professor says that to his student because the paper is empty).

\subsection{Interjections}

The term interjections started to appear in the 13th century from the Latin word interjicere (jacere) in which inter means between and jacere means to throw. Interjections are usually referred to distinct class of elements which create a comparatively stable group of recognizable words and with certain communicative function. English Interjections are over 500 words or one-word utterances that people use in particular situations. There are interjectional forms that are new and occur in the language of popular culture, comic-strips, and pop music, (Jovanović, 2004).

Quirk et al. (1985) depict interjections as "purely emotive words which do not enter into syntactic relations"; Trask (1993) shows an interjection as "a lexical item or phrase which serves to express emotion and which typically fails to enter into any syntactic structures at all"; Crystal (1995) says "an interjection is a word or sound thrown into a sentence to express some feeling of the mind". Thus, interjections are words or items which are semantically rich and constitute state of mind, feelings, emotions, enthusiasm, mockery, laughter...etc. They are considered to be discourse markers that serve a function in communication (Ameka, 1992).

Ameka (1992) splits interjections into two fundamental groups: primary and secondary interjections. Primary interjections are words which are used as an interjection, not in any other sense than, e.g., oops and ouch as in the example below:

Patient: Be careful with that needle!

Dentist: Oops.

Patient: Ouch!

The other group is secondary interjections which are having distinct semantic sense in which speakers use to share their attitudes, e.g., hell and shit as in:

Friend 1: Hell, how are you?

Friend 2: I'm good my favorite shit!

\subsubsection{Interjections for Laughter}

There are many interjections that present a laughter indication. Firstly, they indicate onomatopoeic words which represents sounds, such as:

1) Ahaha (aristocratic sounding laughter)

2) Boff (a big laugh)

3) Guffaw (belly laugh)

4) Hah! (laughter)

5) Snort (a burst of laugh through the noise).

Secondly, they denote secondary interjection for laughter, they are usually addressed by friends or between members of the family like: hell, damn, idiot, shit, gang (refers to a group of friends Ameka (1992), dog. monkey. Bees and idols (Booty, 2002).

\section{Theoretical Background}

\subsection{The Adopted Models}

The adopted models are so helpful in analyzing the data. In this study, the models used for analysis are the theory of Cooperative Principle which consists of Grice maxims and Taflinger's Model. These two models are significant in analyzing comic words.

\section{a. Grice Maxims' Model}

Grice (1975) discusses the cooperative principle which is considered as a guide for communication between two participants within a conversation. He explains four maxims that are components of any conversation:

1) The Quality Maxim:

(1) Do not say what you believe to be false.

(2) Do not say that for which you lack adequate evidence.

2) The Quantity Maxim: 
(1) Make your contribution as informative as required (for the current purposes of the exchange).

(2) Do not make your contribution more informative than required.

3) The Maxims of Relation:

(1) Be relevant.

4) The Maxims of Manner:

(1) Avoid obscurity of expression.

(2) Avoid ambiguity.

(3) Be brief.

(4) Be orderly.

Comic or funny words commonly share the two maxims of manner and relation, but violating these maxims would create sarcasm and mocking. The violation of quality and quantity maxims would establish teasing. In addition to Grice (1975), speech-act jokes involve violating the felicity conditions like illocutionary acts described by Austin and Searle (1969), and the related conversational maxims proposed by Grice (1975). Such violations may be thought funny when they are unintentional. They can become jokes when they are intentional

\subsection{Taflinger's Model}

Taflinger states the following three elements are required for something to be humorous:

1) It must appeal to the intellect rather than the emotions;

2) The situation and its parts (the actions performed and the dialogue spoken) must be inconsistent or unsuitable to the surrounding or associations.

3) It must be perceived by the observer as harmless or painless to the participants.

In addition to the models of Grice and Taflinger, there are many characteristics of comic words presented by Winfried Noth (1999). They are:

1) Comic words have mostly have mostly clear meaning and sometimes implied meaning.

2) They are sometimes written in boldface letters.

3) They usually show onomatopoeic words.

4) They are often interjections (laughter interjections).

5) They can stand alone.

So, the proposed model combines the Cooperative Principle and Taflinger and uses them in addition to some characteristics presented by Winfred Noth (1999).

\section{Data Analysis}

The data for analysis is the American sitcom friends and the British one which is bottom. Both of them are chosen as a data for comic words, because they are sitcoms or funny series which are considered as a helpful tool to be dealt with.

\subsection{Friends}

The American television sitcom Friends is created by David Crane and Marta Kauffman. It is aired from September 22, 1994 to May 6, 2004. It is regarded as one of the greatest TV shows. The characters of this sitcom are: Jennifer Aniston, Courteneny Cox, Kisa Kudrow, Matt Leblanc, Matthew Perry and David Schwimmer. It starts with six friends who live in Manhatttan. The name of the friends are: Chandler Bing, Joey Tribbiani, Ross Geller, Phoebe Buffay, Rachel Green, and Monica Bing.

\subsubsection{The Selected Scripts}

\section{Season 1/Episode 101}

Scene: Monica and Rachel's, Ross is entering.

Ross: Guys? There's a somebody I'd like you to meet. (A monkey jumps on to his shoulder.)

All: Oooh!

Monica: W-wait. What is that?

Ross: 'That' would be Marcel. You wanna say hi? 
Monica: No, no, I don't.

Rachel: Oh, he is precious! Where did you get him?

Ross: My friend Bethel rescued him from some lab.

Phoebe: That is so cruel! Why? Why would a parent name their child Bethel?

Chandler: Hey, that monkey's got a Ross on its ass!

Monica: Ross, is he gonna live with you, like, in your apartment?

\section{Season 1/Episode 113}

Scene: Central Perk, Phoebe is there with her boyfriend Roger, talking to Rachel and Monica.

Phoebe: Oh, honey, honey, tell them the story about your patient who thinks things are, like, other things. Y'know? Like, the phone rings and she take a shower.

Roger: That's pretty much it.

Phoebe: Oops!

Roger: But you tell it really well, sweetie.

Phoebe: Thanks. Okay, now go away so we can talk about you.

Roger: Okay. I'll miss you.

Phoebe: Isn't he great?

Rachel: He's so cute! And he seems to like you so much.

Phoebe: I know, I know. So sweet... and so complicated. And for a shrink, he's not too shrinky, y'know?

Rachel: Okaaay. (To the guys, on the couch) Any of you guys want anything else?

Chandler: Oh, yes, could I have one of those. (Points)

Rachel: No, I'm sorry, we're all out of those. Anybody else?

Chandler: Okay.

Roger: Did I, uh, did I miss something?

Chandler: No, she's still upset because I saw her boobies.

Ross: You what? Wh what were you doing seeing her boobies?

Chandler: It was an accident. Not like I was across the street with a telescope and a box of donuts.

Rachel: Okay, okay, could we change the subject, please?

Phoebe: Yeah, 'cause hello, these are not her boobies, these are her breasts.

Rachel: Okay, Pheebs, I was hoping for more of a change.

Chandler: Y'know, I don't know why you're so embarrassed, they were very nice boobies.

Rachel: Nice? They were nice. I mean, that's it? I mean, mittens are nice.

Chandler: Okaaay, (Gestures) rock, hard place, me.

Roger: You're so funny! He's really funny! I wouldn't wanna be there when when the laughter stops.

Chandler: Whoahwhoah, back up there, Sparky. What'd you mean by that?

Roger: Oh, just seems as though that maybe you have intimacy issues. Y'know, that you use your humour as a way of keeping people at a distance.

Chandler: Huh.

Roger: I mean hey! I just met you, I don't know you from Adam. ...Only child, right? Parents divorced before you hit puberty.

Chandler: Uhhuh, how did you know that?

Roger: It's textbook. (Joey enters with his dad)

Joey: Hey you guys. Hey, you all know my dad, right?

All: Hey! Hey, Mr. Trib! 
Monica: Hey, how long are you in the city?

Mr. Tribbiani: Just for a couple days. I got a job midtown. I figure I'm better off staying with the kid than hauling my ass back and forth on the ferry. (Sees Roger) I don't know this one.

Phoebe: Oh, this is my friend Roger.

\section{Season 3/Episode 321}

Scene: Outside Central Perk, Rachel and Phoebe are helping Monica learn how to roller skate by rolling her between themselves.

Rachel: So, who's idea was it to put everybody in the diner on skates?

Monica: Oh, some idiot customer put a suggestion in the suggestion box.

Phoebe: Oh my God, they took my idea!

Monica: That was you?!

Phoebe: Yeah! Okay, here you go. (rolls her back to Rachel)

Scene: The Moondance Diner, Pete is entering, Monica is on roller skates.

Pete: Hi!

Monica: Hi! Hey, Pete you're back! Hey, check this out. (She starts to skate over to him)

Pete: Wow! Skates!

(She gets just about all the way over to him and falls into his arms.)

Monica: Wow! You're a lot sturdier that Chandler. He crumpled like a piece of paper. So how was you're trip?

Pete: Well... (he holds up a gift he brought her)

Monica: Oh, what'd ya bring me?! (She opens the gift) Awww, hotel toiletries from Japan. Oh, these are gonna go in my permanent collection. You want some coffee? ... then

Monica: (rolling towards the office) I'm quitting!! Woo-hoo! (She rolls through a doorway and out of sight. We then hear a big crash, and see Monica roll past the door the other way.) I'm okay!! I'm all right!!

Phoebe: (to Pete) Wow! That's exciting, you went to Japan, made up a woman.

Table 1. The comic words and their categories

\begin{tabular}{llllll}
\hline Comic word & Category & Meaning & Season & Episode & Line \\
\hline A*s & Teasing & Bad meaning & 1 & 101 & 11 \\
Awww & Primary interjections & Disgust & 3 & 321 & 19 \\
B****s & Mockery & Shows breasts & 1 & 113 & 21 \\
breasts & Teasing & - & 1 & 113 & 26 \\
Huh & Primary interjections & Relief & 1 & 113 & 39 \\
Idiot & Teasing & Expresses stupidity & 3 & 321 & 4 \\
oh & Primary interjections & Emotions to pleasure & 1 & 101 & 8 \\
Oooh & Primary interjections & Emotions to pleasure & 1 & 101 & 4 \\
Oops & Primary interjections & Astonishment & 1 & 113 & 7 \\
Precious & Sarcastic & Expresses the opposite & 1 & 101 & 8 \\
Uhhuh & Primary interjections & understanding & 1 & 113 & 42 \\
Whoah-whoah & Onomatopoeic word & laugh & 1 & 113 & 34 \\
Woo-hoo & Onomatopoeic word & Excitement & 3 & 321 & 22 \\
Wow & Primary interjections & Excitement & 3 & 321 & 14 \\
Wow & Primary interjections & Excitement & 3 & 321 & 26 \\
\hline
\end{tabular}

In the Friends American sitcom, the results show that there are many comic words. The characters use mostly primary interjections or onomatopoeia (like ooh, oh, oops, whoah-whoah, huh, uhhuh, wow, etc.) to reflect the characterization and the essence of laughter. The use of teasing is also emphasized by the appearance of other comic words like: ass, breasts, and idiot. The purpose behind such appearance is for presenting jokes and laughter sense. There is a use of sarcastic category such as precious to imply an opposite meaning for the sake of 
amusement. Furthermore, there is a sense of denoting mockery by the use of boobies to depict the spectacle of the unkind laughter or to make fun of someone.

\subsection{Bottom}

The second sitcom is Bottom which is a British television sitcom produced by Adrian Edmondson and Rik Mayall that originally aired on BBC2 from 17 September 1991 to 10 April 1995 across three series. The show stars Edmondson and Mayall as Edward Elizabeth Eddie Hitler and Richard Richie Richard, two flatmates who live in Hammersmith, West London. This sitcom is characterized by being violent comedy.

\subsubsection{The Selected Scripts}

\section{Season 1/Episode 1}

[Eddie throws across two eggs, which splash out of the frying pan.]

Ha hahaha, ha hahahaa, the old ones are the best ones, aren't they! Who needs girls when you've got your mates! I tell you, there's some things a girl just can't appreciate and Richie's Friday night fryup is one of them. Oil!

[Eddie is drinking from a bottle of oil. He replaces the lid and throws the bottle to Richie.]

Eddie: Ah! Mazola!

Richie: Right then. A little dab of oil... The secret ingredient...

[He picks up a pan and starts to scrape out the contents.]

Come on out, you know you want to! Come on, you've only been in there a week.

[Eddie takes a pint from his jacket pocket.]

Eddie: Ha hahahaaa!

Richie: And then just the last couple of pints... Hoh!

[Richie has noticed some action going on in the house opposite. He takes a pair of binoculars from a hook by the window. The couple notice him ogling them.]

Lovely night!

\section{Season 2/Episode 6}

- Da-la da-la da daa \# After a long hike like that, I'm ready to pitch camp and hit the sack! - I can still see the bus stop from here! - This looks like a good spot! A natural - Shit hole! - Yeah, shit No, no, no! A natural hollow in the lee of the wind.

Fresh water supply.

-The wind coming from Cor! Dear, oh, dear! You'd think people would have more control over their dogs! Look at that! It must've been a Great Dane! We can't camp here! We're not French! Hi-de-ho, on we go! No rest for the hygienic! Dear, oh, dear, who'd be English? Yeah, this is much better here! A much more likely spot! - This is great, isn't it? - What? - This! - No.

-You poor, sad, deformed urban pustule.

-This is real life! Nature, struggle, destiny! Where's your romance? She works in Sketchley's on Saturday.

-I should be going out with her tonight.

-That's a point.

-Where do we sleep? Ha-ha-ha I'm about to blow my trousers off in merriment at Eddie's sarcasm - You mean that's the whole tent? - Eddie, this isn't just a tent.

-This is a World-Ranger Storm-Buster.

-You can go anywhere in that.

- We will as soon as the breeze gets up.

-You can't say anything without some double entendre lurking around the corner! Shall we just unpack and get dinner on the go? All right? I bet you forgot the tin opener! I despair, I really do! I give you one little obligation and what do you do? You forget it! Well, that's where you're wrong because - ha haha ha-ha here it is! - Right, where are the tins? - Shit! Shit! You stupid bastard! Why did you make me forget them? We're gonna starve to death! - We are going to starve to death! - I've got a packet of Chocolate Hobnobs. 
Table 2. The comic words and their categories

\begin{tabular}{llllll}
\hline Comic word & category & Meaning & Season & Episode & Line \\
\hline Ah & Interjection & Expresses joy & 1 & 1 & 9 \\
bastard & Secondary interjections & Mocking & 2 & 6 & 29 \\
Da-la da-la & Sarcasm & laughter & 2 & 6 & 1 \\
Ha hahaha & Onomatopoeic word & Communicates laughter & 1 & 1 & 3,15 \\
Ha-ha-ha & Onomatopoeic word & laughter & 2 & 6 & 17 \\
Hoh & Interjection & surprise & 1 & 1 & 16 \\
Shit & Secondary interjections & - & 2 & 6 & 4 \\
Shit & Secondary interjections & Violence & 2 & 6 & 28 \\
stupid & Secondary interjections & Mocking & 2 & 6 & 29 \\
\hline
\end{tabular}

For the Bottom British sitcom, the results exhibit also the frequent use of comic words. Being in the visible scene, the characters use considerably interjections or onomatopoeia such as (ha hahaha, ah, hoh, da-la da-la, shit, ha-ha-ha, stupid and bastard) to communicate laughter, humor, and excitement. In addition, the characters use sarcasm to display humorous sense during the episode and the repetition of ha-ha word to communicate laughter.

\section{Conclusion}

\subsection{Preliminary Notes}

The job of discourse analysis is to describe how stretches of language become meaningful and unified for their users, taking into consideration their textual, social, and psychological context fully. Three dimensions for the concept of discourse are recognized: language use, the communication of cognition, and the interaction in social situations. The field of discourse is an expanding one, which presents the processes and problems of the use of language and language learning. If someone uses discourse, this means that he or she is using formal and unified written or spoken debate or discussion. Discourse has a relation with utterances in which speakers and hearers share. Discourse has a relation with words also; like comic words. There is a strong connection between discourse and comedy or humour. First, discourse itself becomes a subject matter of comedy; the semantic, morphological, and pragmatic elements consist of comic elements and humorous words. The comprehension and appreciation of humour are determined by the use of interactions in societies of different cultures.

\subsection{Major Findings}

There is a connection between discourse analysis and comedy or comic words in that how people use comic words when they take part in the activity of conversation. There are several types of comedy like comedy of errors, comedy of manners, sentimental comedy, comedy of humors and farce. For comic words, they can mean mocking, teasing, sarcasm or interjections depending on the context. According to Winfried Noth, there is a strong relation between interjections and comic words in that he considers comic words are often laughter interjections.

In both sitcoms, "Friends", the American one and "Bottom", the British one, the results show that there are many comic words. The characters use mostly primary interjections or onomatopoeia (like ooh, oh, oops, whoah-whoah, huh, uhhuh, wow, ha hahaha, ah, hoh, da-la da-la, shit, ha-ha-ha, stupid and bastard) to communicate laughter, humor, and excitement. The use of teasing is also emphasized by the appearance other comic words like: ass, breasts, and idiot, the purpose behind such appearance is for presenting jokes and laughter sense. In addition to the use of sarcasm to display humorous sense during the episode as "precious" for implying opposite meaning in order to amuse the hearers. Furthermore, there is a sense of denoting mockery by the use of "boobies" to depict the show of a little bit tough laughter or to make fun of a specific character. So, from the analysis, the American characters or people uses more comic words than the British ones.

\section{References}

Aaryn, L. G., \& Linders, A. (2016). The Impact of Comedy on Racial and Ethnic Discourse. Sociological Inquiry. https://doi.org/10.1111/soin.12112

Abrams, M. (1981). A Glossary of Literary Terms (pp. 25-27). Hong Kong.

Altenbernd, L., \& Leslie, L. (1989). A Handbook for the Study of Drama (pp. 68-69). New York.

Ameka, F. (1992). Interjections: The Universal yet Neglected Part of Speech. Journal of Pragmatics, 18(2\&3), 101-118. https://doi.org/10.1016/0378-2166(92)90048-G

Booty, A. (2002). The Funny Side of English (pp. 21-22). Pustak Mahal. London.

Boulton, M. (1960). The Anatomy of Drama (pp. 151-153). Great Britain. 
Boxer, D. (2002). Applying Sociolinguistics: Domains and Face-to-Face Interaction (p. 100). Amsterdam. Philadelphia. https://doi.org/10.1075/impact.15

Brooks, C., \& Heilman, B. R. (1999). Understanding drama (pp. 78-79). New York.

Cohn, N. (2012). Comics, Linguistics, and Visual Language: The Past and Future of a Field (p. 2). New York. https://doi.org/10.1057/9781137004109_5

Crystal, D. (1995). The Cambridge Encyclopaedia of the English Language (p. 207). Cambridge University Press.

Dorfman, L., \& Michael, J. (2017). The Sarcasm Handbook (pp. 8-9). China.

Douglas, O. S. (2002). Aristophanes and the Definition of Comedy by M. S. Silk (p. 96). The Classical World. https://doi.org/10.2307/4352728

Dunn, M., \& Aragones, S. (2013). Zounds! A Brower's Dictionary of Interjections (pp. 3-21). New York.

Evaldsson, A. (2005). An Article of Staging Insults and Mobilizing Categorizations in a Multiethnic Peer Group (pp. 763-786). https://doi.org/10.1177/0957926505056663

Grice, P. H. (1975). Logic and conversation. In P. Cole \& J. L. Morgan (Eds.), Speech Acts (pp. 41-58). New York: Academic Press.

Jauregui, E. S. (1998). Situating Laughter: Amusement, Laughter and Humour in Everyday Life. European University Institute, Florence.

Jaworski, A., \& Coupland, N. (2014). The Discourse Reader (pp. 1-3). USA and Canada.

Johnstone, B. (2008). Discourse Analysis (pp. 2-4). Blackwell Publishing Ltd.

Jovanović, V. (2004). The Form, Position and Meaning of Interjections in English (pp. 18-20). Facta Universities.

Kruger, G., \& Kuban. (2006). A Journal of Personality and Social Psychology: Intentions in Teasing: When “Just Kidding” Just Isn't Good Enough (pp. 412-413). https://doi.org/10.1037/0022-3514.90.3.412

Li, X. Q. (2016). A Pragmatic Analysis of Humour words in English Advertisements. English Langange and Literature Studies, 6(2). https://doi.org/10.5539/ells.v6n2p193

Lynne, J., \& Kosove, P. (1977). The Comedia Lacrimosa and Spanish Romantic Drama by Joan (p. 26). London.

Matthews, P. H. (2005). Oxford Concise Dictionary of Linguistics (p. 5). New York: Oxford University Press.

McDowell, J., \& Schffner. (2011). Football, it's a Man's Game: Insult and Gendered Discourse in The Gender Bowl. Discourse and Society (p. 547). SAGE Publications Ltd. https://doi.org/10.1177/0957926511405574

Nöth, W. (1999). A semiótica no século XX. São Paulo: Annablume.

Qurik, R., Greenbaum, S., Leech, G., \& Sartvik, J. (1985). A Comprehensive Grammar of the English Language by Randolph (p. 853). Hong Kong: Longman Group United Kingdom Ltd.

Reddy, V. (1991). Playing with others' Expectations: Teasing and Mucking about in the First Year (pp. 143185). United Kingdom: Basil Blackwell Ltd.

Searle, J. (1969). Speech Acts: An Essay in the Philosophy of Language (pp. 22-29). Cambridge university Press. https://doi.org/10.1017/CBO9781139173438

Stone, W., \& Nettleton, H. (1914). English Drama of the Restoration and Eighteen Century (p. 149). United States of America.

Taylor, K. (2006). Ka-BOOM! A Dictionary of Comic Book Words, Symbols and Onomatopoeia (pp. 11-32). Mora Publications.

Trask, L. (1993). Penguin Dictionary of English Grammar by Larry (p. 144). London.

Van Dijk, A. T. (1997). Discourse as Structure and Process (pp. 2-12). SAGE Publications Ltd.

\section{Copyrights}

Copyright for this article is retained by the author, with first publication rights granted to the journal.

This is an open-access article distributed under the terms and conditions of the Creative Commons Attribution license (http://creativecommons.org/licenses/by/4.0/). 